\title{
Progressão continuada, supervisão escolar e avaliação externa: implicações para a qualidade do ensino*
}

VITOR HENRIQUE PARO Universidade de São Paulo

\section{INTRODUÇÃO}

Pesquisa de caráter qualitativo, realizada de março de 2007 a fevereiro de 2010, no sistema estadual paulista de ensino, teve como escopo geral estudar a estrutura da escola pública fundamental, à luz de um conceito de educação como prática democrática. O trabalho de campo, efetivado durante o ano letivo de 2008, realizou-se em escola que oferece ensino fundamental da primeira à quarta série, localizada na cidade de São Paulo. Subsidiariamente, porque se tratava de estudo sobre a estrutura da escola, foram ouvidas pessoas do sistema de ensino de Aracaju, que tem uma experiência inovadora nesse sentido (Aracaju, 2006). O estudo da "estrutura total da escola" (Cândido, 1974, p. 107), entendida com significado mais amplo do que seu uso vulgar ou do que sua mera configuração formal, deve envolver necessariamente um conjunto variado de temas, cuja discussão possa contribuir para uma compreensão mais ampla da complexa realidade escolar e dos fins a que esta deve servir. Esses temas foram objeto de exame no processo de investigação, e os resultados completos da pesquisa encontram-se em Paro (2010b). Neste artigo,

* Este trabalho é resultado de pesquisa que teve financiamento parcial do CNPq. 
apresento três dos temas examinados - progressão continuada, supervisão escolar e avaliação externa -, cuja característica comum é sua relação com a qualidade do ensino e com a avaliação.

Para adiantar um pensamento que deverá tornar-se mais explícito no decorrer do trabalho, a concepção de qualidade do ensino aqui adotada tem seu fundamento num conceito de educação escolar que não se limita ao adotado pelo senso comum (e, em certo sentido, implícito nas políticas públicas em geral) e que a vê como simples passagem de conhecimentos e informações. $\mathrm{O}$ conceito que adoto vê a educação como formação da personalidade humano-histórica do educando, pela apropriação da cultura em seu sentido pleno, que inclui conhecimentos, informações, valores, arte, tecnologia, crenças, filosofia, direito, costumes, tudo enfim que é produzido historicamente pelo homem e que, numa democracia, o cidadão deve ter o direito de acesso e apropriação.

A "linha teórica" que informa este trabalho, portanto, é aquela consagrada nos clássicos da pedagogia de todos os tempos, implícita nos mais recentes avanços da filosofia e das ciências da educação - corroborada inclusive pelas conquistas mais recentes da neurociência (Damásio, 2009; Kandel, 2009 e muitos outros) -, que concebe o educando como sujeito (autor), que constrói sua personalidade viva à medida que se apropria dos elementos culturais apresentados pelo educador, o que é possibilitado pela prática pedagógica exercida por este, que se faz mediador, não mero transmissor de saberes. Como já demonstrei em outro trabalho (Paro, 2010a), essa prática assume um caráter necessariamente democrático, se por democracia entendermos a "convivência pacífica e livre entre pessoas e grupos que se afirmam como sujeitos" (p. 27).

Assim, contemplar a qualidade do ensino na discussão da estrutura da escola a partir de uma concepção de educação como prática democrática exige certamente a consideração de perspectivas de transformação da escola atual, com análises e propostas que acenem para a superação da relação pedagógica conservadora vigente nos diferentes sistemas públicos de ensino. No que diz respeito aos sistemas de ciclos e progressão continuada, conceitos que serão explicitados na próxima seção deste trabalho, a transformação, na direção da qualidade, precisa considerar a importância da efetiva eliminação da reprovação escolar, a necessidade de aproveitar as lições propiciadas pelas experiências exitosas das duas últimas décadas e a crítica e superação das iniciativas que apenas aproveitaram o pretexto dos ciclos e progressão continuada para seguir não fazendo nada em termos de melhoria do ensino. Com relação à supervisão escolar, como veremos na segunda seção, os dados apontam para a necessidade de superar a tradicional redução de suas funções aos aspectos burocráticos e se encaminhar para um efetivo entrosamento com a coordenação pedagógica interna à unidade escolar e para a valorização de suas funções de assessoria, apoio e aperfeiçoamento da prática docente nas escolas. No tocante à avaliação externa, tema discutido na seção seguinte, a principal exigência 
de mudança com vistas à boa qualidade do ensino é a ultrapassagem dos limitados regimes de exames e provas externas, por sistemas avaliativos que contemplem mais integralmente o conceito de educação como apropriação da cultura e não apenas como "aquisição" (temporária) de conhecimentos.

Assim como a qualidade do ensino, a avaliação escolar é característica que se associa fortemente aos três temas aqui discutidos, embora seu tratamento mais sistematizado seja dado apenas na seção sobre a avaliação externa. Com relação aos ciclos e à progressão continuada, a avaliação escolar é referência obrigatória. Como afirma Sandra Zákia Sousa (2007, p. 35), “dentre todas as práticas e rotinas escolares, aquela que mais diretamente é 'abalada' com a implantação dos ciclos é a avaliação". Mas também a supervisão escolar não deve ser discutida à parte da avaliação, podendo ser analisada inclusive do ponto de vista de suas potencialidades como alternativa de avaliação externa, considerando-se suas virtualidades para uma avaliação em profundidade do processo de aprendizado nas escolas, atributo que falta às chamadas avaliações externas massivas. Estas, por sua vez, apesar de sua notável popularidade, hipervalorizada especialmente por pessoas e instituições pouco familiarizadas com o real significado do processo educativo, precisariam iniciar por ter reconhecidas suas limitações, de modo que não pretendam, em suas conclusões sobre a performance e a formação dos educandos, ir além do que seus precários métodos podem oferecer em termos de diagnóstico e de avaliação educativa. A partir desse reconhecimento, talvez se pudesse avançar para o aproveitamento das vantagens dessas avaliações externas em termos de alcance demográfico, buscando oferecer subsídios avaliativos em escala ampliada, mas que transcendam a mera cata e processamento estatístico de respostas a testes padronizados.

\section{CICLOS E PROGRESSÃO CONTINUADA}

Um dos pontos essenciais relativos à estrutura didática da escola fundamental é a necessidade de superação da tradicional organização seriada do ensino. A esse respeito, tem-se verificado nos últimos anos, especialmente a partir do final da década de 1980, um importantíssimo movimento de tentativas de superação do "regime estúpido das repetições de série” (Teixeira, 1954), por meio da implementação do regime de ciclos e de progressão continuada em vários sistemas de ensino do país (Barreto; Mitrulis, 2001). Esse movimento tem-se fundamentado, em grande parte, na maior conscientização de setores responsáveis pela educação que se convencem, cada vez mais, do caráter antipedagógico da reprovação e percebem que o sistema seriado não se sustenta à luz da teoria pedagógica e tem servido apenas para jogar sobre o aluno a culpa pela incompetência do próprio sistema de ensino em levá-lo a aprender (Paro, 2003).

O sistema seriado de ensino mostra sua procedência antidemocrática na medida em que serve a uma concepção tradicional de escola fundamental, preocupada 
não em ensinar, mas em separar os alunos que podem prosseguir, passando de série, dos que não podem. É um sistema tributário de uma pedagogia baseada no prêmio e no castigo como motivações para o estudo, esquecendo-se da característica básica do bom ensino que é a de ser intrinsecamente desejável pelo educando que, assim, estuda porque quer, fazendo-se sujeito, que é a marca da verdadeira relação democrática.

Progressão continuada e ciclos escolares, embora não tenham o mesmo significado, possuem uma relação muito íntima entre si. A primeira significa, a rigor, a "progressão" em determinado nível de ensino ou ciclo, sem que o aluno tenha de "repetir de ano". O ciclo, em sentido restrito, é entendido como o conjunto de anos durante os quais a progressão tem validade. De um ponto de vista mais amplo, e em consonância com os avanços das ciências da educação, que consideram, por exemplo, as fases de desenvolvimento biopsíquico e social da criança e do jovem, os ciclos são uma forma de organizar o ensino em períodos que levam em conta essas fases do desenvolvimento humano, durante a formação da personalidade, oferecendo ao educando o tratamento pedagógico mais de acordo com sua idade e estágio de desenvolvimento. Aqui não há por que manter a reprovação, mesmo no final de cada ciclo, pois as mesmas ciências da educação já demonstraram, à exaustão, que tal medida é deletéria ao processo ensino-aprendizado. Só aqui, a rigor, podemos falar de progressão continuada em sentido amplo, em que a continuidade da progressão não é barrada nos finais de ciclos, mas estende-se por todo o nível de ensino.

É preciso, por isso, distinguir entre as experiências sérias e preocupadas com a melhoria do ensino e aquelas que, em nome dos ciclos e da progressão continuada, implementaram verdadeiras contrafações desse sistema, apenas suspendendo, ou restringindo, as reprovações anuais - para seguir a moda ou para conseguir obter índices de desempenho do sistema de ensino aparentemente melhores diante da opinião pública -, mas sem instituir uma necessária reforma na própria estrutura didática, para adequar o ensino às múltiplas e diferenciadas necessidades dos educandos no decorrer de seu desenvolvimento biopsíquico e social. Isso tem produzido verdadeiras aberrações, como a de chamar de progressão continuada a um regime que mantém a reprovação como recurso didático (apenas que agora limitada à passagem de um ciclo para outro), ou a entender os ciclos como conjuntos de séries, mantendo toda a filosofia e a prática escolar da seriação, ou, ainda, dividir o ensino em ciclos sem nenhum critério pedagógico, como aconteceu nos sistemas em que apenas se cortou ao meio o ensino fundamental, instituindo dois "ciclos" de quatro séries, praticamente regredindo ao tradicional sistema do primário e ginásio de antigamente.

O que esse sistema de "ciclos", pautado no mero interesse em maquiar estatísticas e em parecer democrático diante dos eleitores, tem conseguido é fazer que todos creiam que a causa do mau ensino é a progressão continuada, aumentando ainda mais a resistência à adoção de uma estrutura didática que não esteja fundamentada 
na reprovação escolar. Na rede estadual de ensino de São Paulo, à qual pertence a unidade escolar em que foi feita a pesquisa de campo, é esse sistema de dois "ciclos" que vigora, tendo quatro anos cada um, ${ }^{1}$ que constituem, na verdade, quatro séries, em completo desacordo com o espírito dos ciclos de aprendizagem, ou seja, o de procurar atender as fases ou ciclos de desenvolvimento biopsíquico e social da criança e do adolescente.

O fator de maior peso na resistência ao sistema de ciclos e de progressão continuada é a oposição generalizada à abolição ou mitigação da reprovação escolar. Em trabalho anterior (Paro, 2003), examinei com certa profundidade as causas socioculturais, psicobiográficas, institucionais e didático-pedagógicas dessa resistência. Aqui vou guiar-me pelas falas dos entrevistados, tecendo eventuais comentários a essas falas, para contribuir para a reflexão sobre o tema.

Segundo Raquel, ${ }^{2}$ diretora da escola, há muito pouca reprovação na Escola Estadual Célia Cintra, onde foi realizada a pesquisa empírica. Mas diz que há pais que pedem para reprovar o próprio filho. "Aí eu acho desumano, porque tudo é um processo e o aluno tem mais um tempo para aprender". A professora Vanessa, da segunda série, acha a progressão continuada uma boa medida. Mas diz que os pais pedem para reprovar. Em termos de avaliação, ela acha que o importante é a avaliação cotidiana, não as provas periódicas. Diz que o sistema estadual de ensino ainda usa notas. Elaine, professora de primeira série, diz que é favorável à progressão continuada, porque dá um tempo maior para o aluno aprender, mas que precisaria ser feito um maior esclarecimento às famílias, porque elas resistem muito à não reprovação.

O esclarecimento aos pais é sem dúvida uma das medidas necessárias a qualquer processo de melhoria da qualidade do ensino e, no caso em pauta, é mais do que justificado diante da cultura da reprovação disseminada no senso comum. Mas a questão do maior tempo para aprender, presente na voz de Raquel e de Elaine, é algo que exige também uma compreensão acima do senso comum. A progressão continuada existe para adequar o ensino aos ritmos das crianças e para levar em conta seus ciclos de desenvolvimento, mas é usual ouvir-se a alegação de que ela só é necessária para dar mais tempo para as crianças das camadas pobres aprenderem, porque elas seriam mais "lentas" ou menos inteligentes, justificando assim o "barateamento" do ensino para essas camadas que passam a ter acesso a um conteúdo curricular minguado com relação aos mais ricos, frequentadores das escolas privadas.

1 A partir de 2010, com a extensão do ensino fundamental para nove anos, o primeiro ciclo passou a ter cinco anos.

2 Para manter o sigilo das fontes, o nome da escola e das pessoas entrevistadas são fictícios. 
Elaine diz que há muito professor também que é contra a progressão continuada. Ela, pessoalmente, é favorável porque vem de uma proposta construtivista, mas existem professores que não aceitam essa proposta. Perguntada sobre o que identifica a proposta construtivista, ela responde:

O que identifica é o professor ser aquele facilitador e o aluno conseguir passar também por aquele processo de aprendizagem dele. O professor só pode ser construtivista quando ele entender que aquele aluno errou e pode acertar depois. A criança está em construção e ele [o professor] vai estar ali ajudando. Diferente da proposta tradicional.

Elaine reporta-se ao Programa "Ler e Escrever", que é um projeto pelo qual o professor fica quatro horas por semana a mais na escola, recebendo um adicional para isso. Ela vem duas vezes por semana à tarde. Diz que o Programa manda dois livros: um de textos e um de atividades. Tem um livro de alfabetização, "que a escola já recebia todo ano". "O professor também ganha um livro, que é um livro de estudo, que a gente usa nessas quatro horas". Isso na primeira e na segunda séries. "Estão mandando livros para que as crianças possam ler, porque não adianta você falar que a criança tem que ler todo dia, se não tem livro para ler, né”. São livros paradidáticos. "Para alfabetização eles mandaram esses dias letras móveis que quem usa, usa muito para alfabetizar". Elaine conclui, dizendo: "Então, eu acho que está tendo um pouco de investimento nessa parte. Então, pode ser que essas provas - Sistema Nacional de Avaliação da Educação Básica (SAEB), Sistema de Avaliação do Rendimento Escolar do Estado de São Paulo (SARESP) - tenham melhores resultados no final".

Observe-se, de passagem, que a professora deve ter assimilado bem as ideias da Secretaria de Educação: a preocupação não é com um ensino melhor, mas que as provas tenham "melhores resultados". Na verdade, como vimos depois, pela imprensa, os resultados nas provas não foram tão bons assim como Elaine esperava. De qualquer forma, essa inversão de valores só pode dar razão à observação de Célestin Freinet, quando Mathieu, seu personagem da obra $A$ educação do trabalho, falando sobre a quebra da harmonia e paz que circunda a escola, diz:

Só a sua escola rompe brutalmente essa paz e essa harmonia, e isso me faz sofrer como um sacrilégio... Uma criança está lendo. Compreendo que está lendo não para saber o que exprimem os signos, mas para submeter-se a uma prova que vocês fiscalizam e sancionam. Depois, a classe se enche de um murmúrio frio, hesitante e úmido, que ressoa monotonamente como uma prece de igreja, um murmúrio dirigido, interrompido de tempos em tempos por uma rude reguada na escrivaninha... (Freinet, 1998, p. 87)

Perguntada sobre o que acha da progressão continuada, Vera Sanches, a coordenadora pedagógica, responde: 
Vitor, eu acho bárbaro [ênfase] a progressão continuada. Bárbaro! Vou te explicar por quê. Porque na progressão continuada, Vitor, o meu aluno, ele não tem que apreender os conteúdos de primeira série, de segunda, de terceira e de quarta. Ele tem quatro anos para apreender aquele conteúdo, não importa em que série. Eu acho bárbaro. Inclusive, com a possibilidade, ao final desse ciclo, se ficou alguma coisinha presa lá atrás que ele não entendeu, ele pode fazer os estudos daquilo. Eu acho bárbaro. Só que, do jeito que foi colocado pra nós, se perdeu muito, a gente empurrou muito aluno com a barriga, a gente não deu conta do aluno, o professor não entendeu. Mas eu acho que ainda está a tempo de salvar isso aqui, tá. Eu até pensei que a secretária da educação fosse acabar com a progressão continuada, porque ela é de coisas, assim, de métodos mais antigos e tal, do reprova e tal. Até me surpreendeu, que ela não acabou com a progressão continuada, ela colocou alguns detalhes aí, de a gente dar conta do aluno até oito anos, mas isso a gente já faz, é conversa...

Indagada sobre a reprovação, se ela acha que é um estímulo, como muitos dizem, porque leva o aluno a estudar por medo de ser reprovado, Vera Sanches diz que não. "Não concordo. Tem que estimular o aluno, tem que mostrar o mundo, tem que dar conhecimento para o aluno... [...] A escola pode oferecer tanta coisa... Ela não tem que reprovar, não. Tem que ensinar e tem que estimular mesmo”.

Vera Sanches é uma das pessoas que mais apoiam a ideia de progressão continuada e de ciclos de aprendizagem na escola pesquisada. Ela reitera mais algumas vezes que acha a medida "bárbara". Continua reportando-se aos malefícios da reprovação e à responsabilidade do professor em ensinar, não em reprovar. Fala das reuniões periódicas que tem com os professores, de seu cuidado em fazer tudo para que o aprendizado seja realmente efetivo. Nas observações que fiz do horário de trabalho pedagógico coletivo (HTPC), percebi esse carinho que Vera Sanches tem com relação ao ensino. Ela acha que o sistema de ciclos exige um número pequeno de alunos por sala porque há momentos em que o aluno precisa de um atendimento individual e as classes muito numerosas não permitem isso. $\mathrm{Na}$ verdade, não é o sistema de ciclos, mas a educação de qualidade que exige isso. Mas não deixa de ser intrigante que as pessoas atribuam aos ciclos condições de realização que antes não eram sentidas como necessárias. Talvez porque, com a progressão continuada, fica mais difícil atribuir ao aluno (via punição pela reprovação) a má qualidade do ensino.

Márcia, a vice-diretora, diz que a progressão continuada é muito boa, mas foi jogada, sem maiores providências.

As pessoas que realmente quiseram aprender e trabalhar, elas foram atrás de cursos. Eu fiz vários cursos quando começou a progressão continuada, eu corri atrás, eu fiz cursos (estava em sala de aula nessa época). Por exemplo, acabava meu período, nós nos reuníamos, as professoras do período, e a gente ia estudar sobre isso. [...] De uma certa forma eu aprendi bem. 
Mas diz que a maioria dos professores não agiu assim e por isso o ciclo não funciona. Márcia diz que a progressão continuada só funciona com melhor formação do professor, mas que é uma boa medida. Ela critica o modo tradicional de ensinar e conclui: "A maioria da culpa do aluno não aprender é do professor". Importante verificar como uma medida que inibe a reprovação leva os professores a sentir necessidade de melhor formação. Talvez porque, no sistema anterior, isso não era necessário. Ou seja, antes se podia ser incompetente, pois a reprovação encobria; agora, não.

Inês, secretária, perguntada sobre a progressão continuada, diz: "Será que os professores, em sala de aula, entendem o que é isso? [...] Acho que o próprio professor não acredita muito no programa". Inês acha que, para funcionar, deveria haver mais formação, mais capacitação para os professores. Diz que concorda com os ciclos, mas mostra-se contraditória. "Eu acho que deveria realmente continuar do jeito que está, porém, tendo a reprovação. Reprovação não é um castigo”. Questionada sobre o fato de que é, sim, um castigo e que é somente o aluno quem paga, Inês concorda e acrescenta que o aluno acaba pegando o mesmo professor. Então, entra em considerações sobre a forma de escolha do professor.

A professora Andreia, da terceira série, diz:

$\mathrm{Eu}$ acho que daria certo, se a gente tivesse uma progressão continuada mesmo. Por exemplo, assim, a criança está na primeira série, ela não aprendeu, por $n$ motivos, mas ela vai para a segunda do mesmo jeito, não aprendendo aquilo que era para aprender na primeira, não aprendeu nada na segunda, e vai para a terceira e a progressão continuada... então, eu acho que o aluno está se prejudicando.

Eis a clássica alegação de que a progressão continuada prejudica o aluno, supondo que ele não aprendeu porque foi aprovado e não porque não lhe ensinaram. A esse respeito, em pesquisa que buscou estudar a opinião dos pais de alunos da escola fundamental sobre a reprovação escolar, Márcia Aparecida Jacomini (2010, p. 77) põe a questão nos devidos termos ao afirmar peremptoriamente: "O baixo rendimento escolar não pode ser atribuído à não reprovação, pois quando não havia restrição às práticas de reprovação isso já acontecia, inclusive esse era o motivo pelo qual os alunos eram reprovados”. Questionada sobre sua argumentação, Andreia refaz o pensamento: "Então, teria que haver um trabalho para que não houvesse essa reprovação, mas que também o aluno aprendesse". Pergunta: "Por que só fazer no fim do ano isso, e não durante todo o processo de ensino?". Andreia ri e reconhece que ainda não parou para pensar.

A justificativa de que a aprovação do aluno que não aprendeu é causada pela progressão continuada também é apresentada pela professora Marilda, da quarta série, que se diz contrária à medida e arrola outros argumentos normalmente apresentados contra a promoção de alunos, como o caráter motivador da reprovação, 
o fato de os pais também serem a favor da reprovação, a segunda chance que se dá ao aluno com a reprovação etc.

Curiosa a opinião de Antônia, auxiliar de professora ${ }^{3}$ da primeira série, sobre a progressão continuada. Sobre o aluno "estar passando, mesmo sem saber", ela diz: "Eu acho isso prejudicial. Ao mesmo tempo eu acho [que ajuda]. Ajuda porque tem aluno que, se você não passa, ele vai continuar com o mesmo professor e não vai entender. Então, [se] você passa, ele vai arrumar um professor, quem sabe na próxima metodologia ele aprende". Sua concepção de progressão continuada diz respeito apenas ao passar de ano. Recrimina o fato de ir passando de ano em ano sem aprender. Diz que o melhor seria que se fizesse a progressão continuada dentro do próprio ano, corrigindo os problemas dos alunos. Depois de uma longa discussão sobre os prós e contras da reprovação, Antônia diz que, então, deveria haver uma progressão, mas com "uma ajuda extra" o ano todo, para o aluno não passar para a próxima série sem saber. Eu digo: isso é que é a progressão continuada. Ela ri, e diz: "Ah! bom, aí então é uma progressão continuada".

\section{COORDENAÇÃO PEDAGÓGICA E SUPERVISÃO ESCOLAR}

$\mathrm{Na}$ Escola Célia Cintra a coordenadora pedagógica, Vera Sanches, tem presença permanente no cotidiano da escola, é extremamente simpática e trata todos com bastante atenção. Durante todo o período de observação na escola, pude testemunhar sua conduta democrática no trato com as professoras e sua implicação com os problemas educacionais. Está permanentemente ocupada, fazendo planejamentos, atendendo docentes, alunos e pais de alunos, executando tarefas corriqueiras e participando de reuniões. Estava presente em todas as reuniões, de pais, de conselho de classe e de HTPC.

O horário de trabalho pedagógico coletivo é a referência básica para a coordenação pedagógica na escola. Nesse horário, os professores, liderados pela coordenadora (liderança às vezes dividida com a diretora), planejam seu trabalho semanal e discutem questões pedagógicas de interesse comum. As professoras entrevistadas mostraram gostar muito da coordenadora pedagógica e enfatizaram a importância do HTPC, mas reclamaram do pouco tempo que é reservado para essa atividade.

Inês, a secretária, pensa diferente, mas referindo-se às escolas em geral, não à Célia Cintra. Ela diz que no HTPC o professor deveria tirar o máximo da

3 O auxiliar de professor é o que o Governo do Estado de São Paulo alardeou como sendo o "segundo professor" na sala de aula, o que não é verdade. Trata-se tão somente de um estudante de graduação, sem nenhuma habilitação docente, que, a partir de um convênio entre a universidade e o governo do estado, "auxilia" o professor da classe, recebendo, para isso, uma espécie de ajuda de custo, que ele usa no pagamento de seus estudos. 
coordenadora. Acha que não precisa aumentar o tempo do HTPC, o que precisa é o professor saber aproveitar ao máximo o tempo que tem.

Andreia, professora da terceira série, acha que o HTPC deveria ser mais pedagógico. Diz que na Célia Cintra tem essa característica, mas não é a regra. Informa que já teve em outra escola um HTPC que atendia bem a seus propósitos. "Era bem pedagógico porque a coordenadora tinha tempo para isso, tinha tempo hábil: não cuidava de outra coisa, só do pedagógico mesmo". Relata que, na segunda-feira, todas as professoras da primeira série se sentavam em círculo, discutiam a programação da semana, faziam um cronograma e já chegavam à sala de aula prontas para desenvolver a matéria. Se algum aluno tinha problema, procuravam resolver, a coordenadora falava com o aluno, "iam descobrindo" o que estava acontecendo e podiam resolver mais efetivamente os problemas.

Uma função que recebe crítica do pessoal da escola é a supervisão escolar, repetindo o verificado em outras pesquisas (por exemplo, Paro, 2000). Quando solicitada a falar sobre a supervisão e assistência pedagógica da Secretaria da Educação, Raquel (diretora) ri, dando a entender que ela praticamente não existe. Diz que a supervisora visita a escola duas vezes por ano, porém preocupada apenas com aspectos formais, como o local onde a merenda é guardada, que é considerado pequeno. Contudo, embora não haja na escola outro lugar disponível, nas duas vezes em que a supervisora veio à escola, os orçamentos apresentados a ela para construir um recinto maior foram reprovados porque muito caros. Diz também que do período que trabalha em direção nunca houve um supervisor que desse assistência pedagógica à escola. "Eu tinha uma supervisora assim que era meio sui generis, ela chegava às dez horas, numa escola que eu fazia noturno, e ela ia para o pátio catar papel de bala, falar que estava tudo muito sujo... Essa foi a que mais atuou, assim, fora da sala da direção".

Vera Sanches, coordenadora pedagógica, diz que a supervisora visita a escola duas vezes por ano, só. Ela reclama também das reuniões que ela tem de frequentar periodicamente na Diretoria de Ensino (DE). Diz que nessas reuniões os supervisores e outros integrantes da DE

dão subsídios, conversam, material belíssimo... Eu sei que não adianta ter tudo isso e a escola não funcionar. Agora, outra parte, Vitor, você precisa ver o desespero geral: a escola aqui precisando da gente e nós presas lá, das oito até às cinco [da tarde], sendo que da vez passada foi até as cinco e dez.

Pergunto a Vera Sanches: "Mas o que fica o coordenador ou coordenadora fazendo, lá? Ouvindo?”. Resposta: “Ouvindo, fazendo oficinas que a gente já cansou de fazer, já faz há trezentos anos, discutindo os mesmos problemas... e a gente fica lá, lendo textos e.... nós temos de ficar lá...”. Pergunto, então: “E a supervisão?”.

Ih! Lá vem você com a história da supervisão... Aliás a supervisora esteve aqui essa semana, depois de muito tempo. Mas sabe por que que ela veio aqui? 
Porque a dirigente mandou. $\mathrm{E}$ sabe por que que a dirigente mandou? Porque a dirigente se enganou. [...] Ela começou a questionar os problemas que a gente não tinha. [E ela disse:] "Ué, porque será que a dirigente me mandou aqui? Não era nessa escola de ciclo dois". Eu falei: "Não, esses assuntos não são da nossa escola de ciclo dois". Inda brinquei com ela: "Você está no defunto errado". Ela falou "Estou mesmo". Então, quando surge algum problema, Vitor, então elas vão. Ela veio aqui porque [achou que tinha problema]. Tanto que ela nunca vem. Ela nunca vem. [...] Ela fala que é porque aqui não tem problema. Oba! Não tem problema... Vamos pensar no futuro, vamos dinamizar as atividades, vamos ver, né.

Já Vanessa, professora da segunda série, diz que a supervisora, quando vem à escola, só sabe ficar criticando as coisas. Diz que, inclusive, entra em sala de aula para observar o trabalho do professor.

Ela veio no primeiro dia de aula. E um aluno falou assim: "Professora, eu posso sentar do seu lado?". Eu falei: "Pode, põe a cadeira aqui que a gente vai fazendo". (Esse aluno até não está mais comigo) Ela já reprovou: "Não tem lugar para ele? Por que que ele não..." Começou a gritar na frente dos alunos. Eu falei: "Calma, ele me pediu ajuda" [...] Eu acho que ela podia chegar, perguntar, [não gritar]... A sala é minha, afinal de contas, eu é que estou lidando com ela.

Indagada se há supervisão na escola, a professora Marilda, da quarta série, ri e diz: "Olha, eu vi duas vezes a supervisora vir aqui. Agora, o que se discute, não sei. Porque não entra na sua sala de aula. Para falar que não entrou na minha sala de aula, entrou no início do ano porque estava com vazamento, só para isso". Em outras palavras, Marilda informa que supervisão mesmo não existe. "E não é só aqui, não; é no geral".

Andreia, professora da terceira série, enfatiza a importância da assessoria externa, e diz que a escola precisa, sim, de supervisão: "Como é que posso ser uma professora que vai ensinar para a cidadania, se eu nunca aprendi isso?”. Mas, perguntada se a supervisão aparece na escola, ela responde: "Contato com o professor, não, mas eu ouvi dizer que eles vêm aqui na secretaria. [...] Olham documentos, não olham [o pedagógico]. Talvez se tiver um documento meio bem diferentinho eles vão até a professora, mas não sei”.

Inês, secretária, tem uma impressão diferente das professoras a respeito da supervisora. $\mathrm{E}$ acha a supervisão muito boa, com relação às coisas da secretaria. "Da minha parte, todas as vezes que eu precisei [...] sempre esteve presente". Diz que, em comparação com as outras escolas onde trabalhou, as supervisoras são mais presentes na Escola Célia Cintra. Considerando que, por informação das educadoras, ela só vem duas vezes por ano, imagine nas outras escolas, então... De qualquer forma, esse depoimento de Inês parece confirmar, em parte, a alegação de outras depoentes de que a supervisão se interessa mais pelo burocrático. 


\section{AVALIAÇÃO EXTERNA}

Como toda atividade humana, a educação não apenas é suscetível de avaliação, mas tem a avaliação como elemento necessário de sua constituição.

A avaliação usualmente se dá em dois momentos. Primeiro: durante o processo de produção, a avaliação se faz presente imprescindivelmente, na medida em que, para o processo ter êxito no alcance do objetivo, é preciso avaliar ininterruptamente as atividades de sua realização, para que elas estejam de acordo com o projeto ou o caminho traçado para se chegar ao fim almejado. Segundo: diante do produto já pronto, é possível avaliá-lo para averiguar a sua qualidade, ou seja, em que extensão o produto é portador dos atributos e das características que dele se espera. Pode-se então falar, respectivamente, em avaliação em processo e avaliação de produto. ${ }^{4}$

Quando o produto é um objeto (um não sujeito), sua avaliação pode ser feita com total ou quase total independência em relação ao processo de produção. Por exemplo, um produto industrial, como uma geladeira ou um automóvel, pode ser avaliado objetivamente "descolado" de sua produção, bastando que se verifiquem suas características e se constate em que medida esse produto atende ao uso que dele se espera. Não se está dizendo que tal produto prescinda da avaliação em processo para ser produzido - produto nenhum prescinde dessa avaliação. Significa apenas que a avaliação do produto se torna independente de seu processo de fabricação.

Isso não tem validade, entretanto, quando o produto não é um simples objeto, mas um sujeito, como é o caso do produto da educação. Nesse caso, a avaliação do produto torna-se extremamente problemática e só pode dar-se com relação a um número muito limitado de seus elementos constitutivos. Se o objetivo da educação escolar é a constituição da personalidade humano-histórica do estudante, ou melhor, daquela "porção" da personalidade que ela se propõe construir (já que a personalidade de um ser humano é, para todos os efeitos, sempre inacabada), uma avaliação completa do produto assim constituído terá por escopo a averiguação do conjunto completo da cultura por ele apropriada.

Parte dessa cultura poderá, ainda que de modo precário, ser verificada mais ou menos "objetivamente" ao final do processo. Estamos falando dos conhecimentos e informações que o educando adquiriu e que podem, em parte, ser avaliados por meio de uma prova ou exame em que se procura aferir, por meio de testes ditos objetivos ou perguntas abertas, em que medida ele reteve esses conteúdos. Mesmo sem considerar sua parcialidade, pois que cuida apenas de um dos elementos da cultura,

4 A rigor, há um terceiro momento que, na verdade, precede esses dois. Trata-se da avaliação (ou valoração) que se dá no momento que antecede o próprio estabelecimento do objetivo a ser alcançado, quando é criado determinado valor do qual derivará tal objetivo (essa derivação está referida em Paro, 2010a, p. 24-25). Não tratarei desse momento da avaliação aqui, pois estou supondo o objetivo já estabelecido. 
esse tipo de avaliação será sempre precário uma vez que - sem falar da relatividade dos valores ou do ponto de vista de quem julga as respostas oferecidas - nunca se saberá se o conhecimento apresentado permanecerá para além do momento da prova ou exame ou se se extinguirá em breve tempo sem se incorporar verdadeiramente à personalidade do indivíduo.

Ademais, os exames, além de serem um recurso precário, só podem ser aplicados para aferir uma pequena parcela da cultura que supostamente compõe a personalidade do aluno educado, ou seja, os conhecimentos e informações. Mas educação não é apenas isso.

Como mediação para a apropriação histórica da herança cultural a que supostamente têm direito os cidadãos, o fim último da educação é favorecer uma vida com maior satisfação individual e melhor convivência social. A educação, como parte da vida, é principalmente aprender a viver com a maior plenitude que a história possibilita. Por ela se toma contato com o belo, com o justo e com o verdadeiro, aprende-se a compreendê-los, a admirá-los, a valorizá-los e a concorrer para sua construção histórica, ou seja, é pela educação que se prepara para o usufruto (e novas produções) dos bens espirituais e materiais. $\mathrm{E}$ tudo isso não se dá como simples aquisição de informação, mas como parte da vida, que forma e transforma a personalidade viva de cada um, nunca esquecendo que "cada um" não vive sozinho, sendo então preciso pensar o viver de forma social, em companhia e em relação com pessoas, grupos e instituições. A educação se faz, assim, também, com a assimilação de valores, gostos e preferências, a incorporação de comportamentos, hábitos e posturas, o desenvolvimento de habilidades e aptidões e a adoção de crenças, convicções e expectativas. (Paro, 2001, p. 37-38)

Não se pode, por isso, quando se trata do produto educacional, contar apenas com a avaliação de produto propriamente dita. Esta precisa ser enriquecida com a avaliação de processo. Observe-se que, em virtude da especificidade da educação, bem como do processo educativo e de seu produto, a avaliação em processo, além de ser necessária para o êxito na confecção do produto, é chamada também a auxiliar na avaliação final, ou seja, na avaliação de produto. Explico. Enquanto um objeto qualquer se deixa avaliar depois de pronto, o produto da educação, por ser sujeito, dotado de vontade, e em virtude das qualidades que o caracterizam, e que precisam, portanto, ser avaliadas, não pode ser avaliado pelos sistemas usuais de aferição de um objeto qualquer, nem pelas provas e pelos testes utilizados para aferir conhecimentos:

[...] uma coisa, por exemplo, é responder positivamente a uma questão sobre a importância da participação política, ou dos aspectos deletérios da corrupção ou do preconceito racial; outra bastante diferente e muito mais complexa é desenvolver, na vida real, as convicções, as posturas e os comportamentos adequados a essas verdades. (idem, p. 38) 
Sendo assim, a avaliação de processo não se aplica apenas com vistas ao sucesso da atividade educativa (embora isso não seja pouco), mas também tendo em mente a avaliação de produto, porque, na dificuldade de se avaliar o produto pronto, a partir do exame de suas qualidades, só resta apostar no processo pelo qual ele passou. Ou seja,

embora não se possa colocar o ser humano em "situação de laboratório" para verificar se ele foi ou não bem educado, para saber se a escola foi produtiva (se teve ou não êxito em sua intenção de educá-lo convenientemente), é possível planejar e dispor os processos pelos quais se produz essa educação de uma forma na qual se possa apostar, com certa segurança, que se conseguirão os resultados desejados. (idem, ibidem)

Diante disso, a política educacional interessada na boa qualidade da educação escolar e portadora de uma visão de educação como apropriação da cultura, com vistas à formação de personalidades humano-históricas, procurará investir seus esforços na melhoria do processo de trabalho escolar, ciente de que é aí, no chão da escola, que se pode garantir a boa educação e permanentemente se informar de sua qualidade.

José Pacheco, durante muitos anos professor na Escola da Ponte, em Portugal (Pacheco, 2009), e um dos idealizadores de sua organização e funcionamento, é bastante contundente ao fazer a crítica ao sistema de provas tradicionais:

Os alunos da Ponte obtêm excelentes desempenhos em provas nacionais e vestibulares. Porém, consideramos isso irrelevante. Um vestibular - à semelhança de outros absurdos - nada avalia. Lamentamos que os ministros reconheçam a falibilidade do vestibular, mas se limitem a introduzir tímidas operações de cosmética, não o extinguindo, e alimentando a indústria do cursinho. Uma prova é um mero instrumento de discriminação, de seleção arbitrária, até mesmo de exclusão escolar e social. E, se outra razão não houvesse para acabar de vez com as provas, uma razão se imporia. Associada à ideia de prova, há sempre a probabilidade de utilização de "cola". Para cada sala de exame que se preze, são escalados professores que, supostamente, são a garantia de que os examinados não "colam". Os "vigilantes" partem, pois, do pressuposto de que todo aluno é, até prova em contrário, potencialmente desonesto. Haverá princípio mais antipedagógico que este? (p. 2)

Em outro momento, ao fazer a crítica à escola tradicional e a seu sistema de provas, o mesmo autor realça a importância da avaliação contínua, durante todo o processo de ensino:

Na Ponte, cada aluno avalia-se quando quer. Quando alcança o domínio de uma destreza, quando adquire um conteúdo, manifesta essa aquisição. Quando atinge um objetivo, quando conclui uma pesquisa, partilha as descobertas. Por essa razão, não faz qualquer sentido a avaliação simultânea de dois ou mais 
alunos. Também não faz sentido aplicar prova. Na dita "escola tradicional", os rituais a que dão o nome de prova (e que nada provam) são meros exercícios de violência simbólica. $\mathrm{E}$ as classificações que neles se baseiam são, também, tão pouco rigorosas quanto inúteis. Por essa razão, não afixamos classificações que comparam alunos. E fundamentamos junto ao ministério essa decisão. Que me perdoe o leitor a presunção, mas o ministério nunca contestou a nossa argumentação. (idem, ibidem)

Do que vimos até aqui, portanto, a avaliação por meio de exames ou provas, durante o processo ou após seu término, é uma das alternativas mais pobres para se medir a eficácia do ensino, especialmente quando utilizada isoladamente. Sua validade torna-se mais duvidosa ainda quando se trata da escola tradicional vigente, que não oferece motivações intrínsecas à atividade de ensino-aprendizado, tornando-a enfadonha e levando o educando a emprestar seu esforço apenas para "livrar-se do estudo" (Paro, 2010b, p. 59-60), o que resulta numa atitude defensiva de estudar a "matéria", ou memorizá-la, apenas nas vésperas dos exames, comprometendo consideravelmente a retenção dos conteúdos envolvidos.

Além de insuficiente como indicador da qualidade da educação, pois se presta a aferir (precariamente) apenas um dos elementos da cultura, os exames e provas podem ser também bastante nocivos para a própria qualidade da educação, particularmente quando eles passam a ser o balizador de todo um sistema de ensino. Não só o aluno passa a estudar apenas para passar de ano ou receber o diploma, mas o objetivo da escola passa a ser, não educar e formar cidadãos, mas obter altas pontuações nos sistemas oficiais de avaliação externa.

De outro lado, os tomadores de decisão nos altos cargos dos sistemas educacionais também pautam suas "políticas" na busca de melhores pontuações, confiando na importância desses sistemas de "avaliação" externa, e pressionando as autoridades escolares a agirem de acordo com o ideal de superar as pontuações ínfimas verificadas. Assim, do alto de seu desconhecimento do fato educativo, e em sua ambição (e ilusão) de conseguir melhor desempenho nas provas, tomam medidas e implementam projetos com o claro objetivo de "treinar" as crianças a responderem corretamente os testes. $\mathrm{Na}$ escola pesquisada, tive a informação de que o material "pedagógico" enviado pela Secretaria de Educação tinha o objetivo de preparar as crianças para responderem as perguntas e exercícios do SARESP. Em síntese, o que acaba pautando a educação escolar não é o objetivo de construir personalidades, mas de formar seres que respondam adequadamente esses exames. Se a maior parte deles, no futuro, só guarda uma parcela insignificante desse conteúdo, como aliás acontece, pouco importa, do ponto de vista dos formuladores de políticas educacionais.

O esforço que o Estado não despende em supervisão e apoio pedagógico à escola parece que ele "compensa" despendendo-o em "avaliação" externa. Assim, a sanha "avaliacionista" que tomou conta das políticas públicas federal, regionais 
e locais dos últimos anos conseguiu apropriar-se do que há de pior em termos de avaliação na escola tradicional e disseminá-lo a todo o país, como se fosse a salvação da educação. A mídia de modo geral, os poderes governamentais e boa parte dos analistas de políticas educacionais, quase sempre que tocam no assunto da escola pública, o fazem "ancorados" nos dados de "indicadores" da qualidade da educação pública, tanto nacionais (como SAEB, Prova Brasil), quanto regionais (como o SARESP, no estado de São Paulo).

$\mathrm{O}$ fato curioso (e muito preocupante) é que esse assunto passou a dominar a pauta do ensino no país de tal maneira que a discussão sobre educação escolar e política educacional parece "movida" pelos dados divulgados pelos órgãos responsáveis pelos exames externos, intensificando-se ou arrefecendo-se de acordo com o surgimento ou a entressafra de novos dados. Isso ocorre como se não houvesse uma enorme multiplicidade de desafios e problemas educativos à espera de discussão e encaminhamento. Mais uma vez, pode-se perguntar até que ponto não é a ignorância sobre a educação e sobre sua complexidade e riqueza que leva boa parte das pessoas ligadas à política educacional a restringir-se a dados estatísticos muitas vezes questionáveis quanto a seus significados.

Alfred North Whitehead, para quem "um sistema de exame externo comum é fatal para a educação” (Whitehead, 1969, p. 21), ao falar sobre um processo de ensino que se veja livre das "ideias inertes", é bastante incisivo sobre o caráter deletério dos exames externos. Diz ele:

O melhor processo dependerá de diversos fatores, nenhum dos quais pode ser negligenciado, a saber o talento do professor, o tipo intelectual dos alunos, suas perspectivas na vida, as oportunidades oferecidas pelo ambiente imediato da escola e fatores correlatos dessa espécie. É por essa razão que os exames uniformes externos são tão perniciosos. Nós não os denunciamos por sermos fantasistas e gostarmos de denunciar as regras estabelecidas. Não somos assim tão infantis. Naturalmente, tais exames também têm sua utilidade para testar a negligência. A razão de nosso desprazer é muito definida e muito prática. O sistema destrói a melhor parte da cultura. Quando se analisa sob o ponto de vista da experiência a tarefa central da educação, descobre-se que seu desempenho feliz depende do ajustamento delicado de muitos fatores variáveis. A razão é que estamos tratando com mentes humanas e não com matéria morta. A evocação da curiosidade, do critério, do poder de dominar um complicado emaranhado de circunstâncias, o uso da teoria ao fazerem-se previsões em certos casos - todos esses poderes não devem ser comunicados por uma regra fixa incluída num programa de matérias de exame. (idem, p. 17 , grifos meus)

O que usualmente se ouve dizer é que alguma coisa esses exames avaliam, e, em virtude da magnitude dos problemas da escola, acabam chamando a atenção 
para o fraco desempenho do ensino público em geral. Uma representante da Secretaria de Educação de Aracaju, ouvida nesta pesquisa, ${ }^{5}$ menciona esse aspecto ao afirmar que as avaliações externas, ao existirem, vieram dar importância à educação, independentemente de tais avaliações serem adequadas ou não. Diz ela que

a divulgação desses indicadores, por si só, já veio balançar muito a escola. Aqui na nossa realidade veio balançar muito. Pela primeira vez, eu vejo pessoas, gestores, que nunca estavam preocupados com isso, estão preocupados [...] em melhorar o nível de aprendizagem do seu aluno... Ver que a escola não pode estar preocupada apenas com almoxarifado, com merenda etc., que as questões administrativas não podem se sobrepor às condições pedagógicas [...] Às vezes eu mesmo coloco para eles: a gente se envolve tanto na burocracia, nos problemas administrativos que a gente termina deixando um pouco o pedagógico de lado.

Tudo bem que uma profissional sensível, como se mostrou a representante da Secretaria de Educação de Aracaju, pense dessa forma e procure maneiras de implementar reformas no sistema de ensino. Entretanto, de modo geral, não é isso que tem acontecido. Antes de tudo, não parece ser necessários programas de tão grandes dimensões - consumindo verbas vultosas que poderiam ser aplicadas na melhoria do ensino - para perceber a atual situação de nossas escolas. Se não fossem os inumeráveis estudos de toda ordem a denunciar essas mazelas, bastariam algumas visitas com pequenas permanências em alguns estabelecimentos de ensino do sistema e a vivência de seu cotidiano, dentro e fora da sala de aula, para conscientizar-se dos múltiplos problemas aí existentes. Além disso, a divulgação dos indicadores parece não ter movido as autoridades educacionais no caminho correto, pois, em lugar de oferecerem melhores condições de trabalho ou de introduzirem mudanças na maneira de ensinar, os sistemas de ensino, em geral, têm reduzido seus programas de governo praticamente à implementação de mais "avaliações" externas, estabelecendo metas irrisórias de aumento das pontuações e, mesmo assim, não conseguindo vê-las efetivadas.

$\mathrm{Na}$ escola pesquisada, pôde-se perceber o impacto das avaliações externas na opinião dos entrevistados. De modo geral, houve críticas à medida, mas algumas pessoas se posicionaram positivamente em relação a ela. Na verdade, a concordância se dá muito mais com a necessidade de avaliação do que com os sistemas existentes em si. Vanessa, professora da segunda série, acha que o SARESP consegue fazer

5 O trabalho de campo da pesquisa, conforme anunciado na Introdução, incluiu entrevista com profissionais da educação do sistema municipal de ensino de Aracaju, que tem uma experiência inédita de direção colegiada, em que, em vez de um diretor, a escola é dirigida por um colegiado composto por três coordenadores (Aracaju, [2003], 2006; cf. Paro, 2010b). 
alguma coisa em termos de avaliação. Márcia diz que fazer a avaliação externa "é bom, sim". A escola é que tem de usar os resultados para tentar melhorar seu desempenho.

Já Elaine, professora da primeira série, acha que as avaliações externas não estão muito preocupadas com o que o aluno aprende. Diz que, talvez agora, com o "Ler e Escrever", se consiga melhorar alguma coisa e ter sentido a avaliação do SARESP. Depois de apresentar o "Ler e Escrever", Elaine conclui: "Então, eu acho que quando você investe, você tem que cobrar um pouco, né. Mas quando não há nada para oferecer, nada de concreto para você trabalhar, eu acho que essas provas ficam mesmo para eles terem os números deles, para eles provarem alguma coisa...”.

Por sua vez, a coordenadora pedagógica Vera Sanches é taxativa em sua oposição ao SAEB: "Aliás, agora em maio, minha segunda série vai fazer o SAEB, que é uma prova tradicional, horrorosa, chata e que não mede nada". Diz que o SAEB era feito nas quartas séries e agora é feito para as segundas séries também. ${ }^{6}$ Segundo Vera Sanches, a E. E. Célia Cintra ficou em segundo lugar em matemática, no SAEB.

Inês, secretária, diz: "Eu não sei... Para mim eu acho que é um pouco de enganação". Reclama que existem metas, bônus etc. só para o professor, mas para o funcionário não, "porque o nosso bônus é realmente irrisório". Ao fazer a crítica do SAEB, SARESP e Prova Brasil, Inês demonstra uma lucidez que talvez falte a nossos administradores da educação. "O professor naquela semana que vai ter a prova, ele vai se dedicar, a criança vai estar ali condicionada, tem que acertar todas aquelas bolinhas, tudo bonitinho. Mas será que realmente ela sabe, ela está aprendendo?”.

A auxiliar de professora, Antônia, acha que as avaliações do tipo SARESP e SAEB são o único modo que o Estado tem de averiguar a qualidade da educação. Mas diz que há escola, ou professores, que burlam os exames. "Porque tem muita avaliação que o professor ajudou. Não aqui nesta escola. Não soube disso não. Mas eu tenho colega que trabalha que [fez] todinha a avaliação do menino".

Sobre as avaliações externas, diz Andreia, professora da terceira série: "Eu acho que não está na realidade. Nós estamos trabalhando de uma forma e isso vem de uma outra forma. Às vezes, o aluno diz assim: 'não sei'. Mas não é que não sabe. Para nós,

6 Vera Sanches (e outras professoras), às vezes chamam genericamente de SAEB as avaliações externas feitas pelo Instituto Nacional de Estudos e Pesquisas Educacionais Anísio Teixeira (INEP). As avaliações do SAEB, de caráter amostral, são aplicadas nas primeiras e quartas séries do ensino fundamental, além de no terceiro ano do ensino médio. Nessa fala, Vera Sanches pretende referir-se à Provinha Brasil, que é realizada nas segundas séries do ensino fundamental e que, como a Prova Brasil, que se aplica nas quartas e oitavas séries do mesmo nível, são aplicadas em todas as escolas urbanas do país com mais de vinte alunos. Para mais informações, consultar a página do INEP na internet: <http://www.inep.gov.br >. Para uma visão crítica da Provinha Brasil, veja-se o excelente artigo de Maria Teresa Esteban (2009). 
nós que estamos [trabalhando de outra forma]". Diz que, agora, com o novo sistema, a Escola Célia Cintra está procurando adequar-se ao SARESP, seguindo a orientação da Secretaria de Educação. Mas reafirma: "Eu acho que está um pouco fora da real".

Raquel, a diretora, acha importante uma prova externa. Mas não concorda com rankings etc. Diz que a Diretoria de Ensino manda o ranking das escolas, com o que ela não concorda. Acha que cada escola deve ter o seu resultado, mas não se deve divulgar para todo mundo. Isso seria antiético. Diz que concorda com as expectativas de aprendizagem que se tem com relação às escolas. E que se faça uma prova externa, já que é importante uma avaliação por quem está fora da escola. Avaliação do aluno, do professor e do sistema. Mas acha ridículo o ranking de escolas. Baseada nesse ranking, a Secretaria deverá dar um bônus para as melhores escolas, ou seja, para as escolas que alcançarem as expectativas da Secretaria da Educação.

Não se precisa realçar a perversidade dessa medida. Primeiro porque ela parte de um diagnóstico falso, o de que o problema da escola reside apenas na capacidade e no empenho dos professores. $\mathrm{Na}$ verdade, existem inúmeros outros fatores, a maioria deles fora do alcance do pessoal escolar: número absurdo de alunos por sala, más condições objetivas da escola (prédio inadequado, falta de material de limpeza, carteiras em más condições etc.), falta de material escolar, falta de assessoria pedagógica, falta de professores em várias disciplinas etc. Acontece que esses problemas e sua magnitude variam de acordo com a população usuária. Nos bairros e locais em que a população é menos desprovida de recursos, mais letrada e com maior acesso a informações relevantes, os usuários tendem a ter maior poder de reivindicação, conseguindo neutralizar em alguma medida os problemas apontados. Por esse motivo - e também em virtude da melhor preparação que os filhos dessas camadas já trazem de casa e que facilitam seu desempenho escolar -, essas escolas tendem a ter algum progresso em seu esforço adicional ou a ter resultados melhores do que as escolas com piores condições de trabalho, mais abandonadas pelo poder público e que, por isso, deveriam ter prioridade na melhoria de atendimento. São precisamente estas últimas que serão punidas por seu mau desempenho e que não receberão os "bônus" que as menos necessitadas recebem, contribuindo, assim, para aumentar a diferença entre os dois infortúnios.

\section{SÍNTESE E CONCLUSÕES}

Embora, como bem assinala Robert Stake (1983), o mais importante na abordagem qualitativa de pesquisa não seja o oferecimento de generalizações formais, é possível apresentar algumas sínteses "provisórias" a respeito dos temas aqui

7 Não deixa de soar um pouco hipócrita chamar de "bônus" aquilo que deveria compor um salário justo, que o Estado sonega e depois repõe (em parte) apenas para alguns. 
tratados, na expectativa de que os dados e interpretações oferecidas possam ensejar, ao usuário de pesquisas, interpretações complementares ou alternativas, que contribuam para o desenvolvimento teórico da área de políticas públicas em educação.

Uma das mais importantes inovações em direção à superação do modo tradicional de tratar o ensino deu-se na tentativa de superação da estúpida seriação (Teixeira, 1954), pela introdução dos ciclos de aprendizagem em vários sistemas municipais de ensino, a partir do início da década de 1990. Houve também sistemas, como o do estado de São Paulo, em que se introduziu um arremedo do regime de ciclos, com a permanência, e até intensificação, da seriação.

A maior resistência aos ciclos por parte de professores, pais e sociedade em geral diz respeito ao apego à reprovação escolar e à oposição à progressão continuada que integra o sistema de ciclos. A reprovação tem sido, tradicionalmente, a maneira mais efetiva de transferir para o educando a culpa pelo mau ensino oferecido pela escola. Sua eliminação pura e simples resulta na "passagem", para as próximas séries ou anos, de muitos alunos que não apreenderam um mínimo de conteúdo correspondente às séries ou anos que frequentaram. Isso tem provocado resultados contraditórios. Por um lado, tem deixado mais à mostra a incompetência da escola: se antes o "mau" aluno era reprovado e "evadido" da escola, agora ele lá permanece, mas sem ter aprendido, evidenciando a incompetência da escola para ensiná-lo. Por outro lado, o passar de ano mesmo sem saber tem sido entendido, muitas vezes, como culpa do sistema de ciclos e progressão continuada, que passa todo mundo e que, por isso, o aluno não se preocupa em estudar. As pessoas não conseguem entender (e muitos professores estimulam esse equívoco junto aos pais) que o que produz o não aprendizado é o não ensino ou o ensino incompetente (este é que precisa ser mudado) e não a promoção do aluno (esta é inerente ao bom ensino). Diante disso, a solução mais óbvia é a implantação dos ciclos e da progressão continuada, não para maquiar estatísticas, mas como apenas uma das medidas a integrar uma política, ou um programa, de melhoria do ensino em todos os sentidos.

Um dos pontos que têm merecido as maiores críticas dos educadores escolares no sistema de ensino do estado de São Paulo diz respeito à precária assessoria pedagógica oferecida às escolas. Segundo os depoimentos captados no trabalho de campo, a supervisão pedagógica praticamente não existe, restringindo-se as visitas do supervisor de ensino a problemas de cunho burocrático. Ao mesmo tempo, a coordenação pedagógica interna à escola, além da ação do coordenador pedagógico (que foi elogiada no trabalho de campo), tem seu ponto mais importante no HTPC, que precisaria ser valorizado, com mais tempo disponível e o acréscimo de outras atividades que incluam também o cuidado com a formação do professor em serviço.

De modo geral, a avaliação externa (SAEB, Prova Brasil, SARESP etc.) expressa boa parte dos equívocos das políticas educacionais vigentes. Apesar de hipervalorizada, sua contribuição em termos de medida da qualidade do ensino é muito precária. O produto da educação, entendida como prática democrática, não 
se deixa avaliar pelos recursos comumente usados na aferição das qualidades de um mero objeto. Os tradicionais exames e provas só conseguem medir um dos elementos (o conhecimento) que compõem a cultura incorporada na personalidade viva do educando, e mesmo assim de forma muito limitada. Assim, os responsáveis pelas políticas públicas, ao darem atenção exagerada a suas avaliações externas, além de atestarem sua ignorância sobre a natureza do produto a ser avaliado e sobre a forma de produzi-lo, gastam somas vultosas de recursos que deveriam ser endereçados para a melhoria do ensino. Em suma, diante da incompetência em diagnosticar e curar o doente, aumentam o tamanho e sofisticam o modelo do termômetro, na esperança vã (e absurda) de diminuir a febre, não de curar o paciente.

\section{REFERÊNCIAS}

Aracaju. Lei n. 3.075, de 30 de dezembro de 2002. Dispõe sobre a gestão democrática da Rede de Ensino do Município de Aracaju. In: SINDIPEMA. Democratização das escolas da Rede de Ensino do Município de Aracaju: Leis 3.074 e 3.075 de dezembro de 2002. Aracaju: Sindipema, [2003], p. 15-26.

Aracaju. Secretaria Municipal de Educação. Escola aberta SEMED: vamos todos construí-la. Aracaju: SEMED, 2006.

Barreto, Elba Siqueira de Sá; Mitrulis, Eleny. Trajetória e desafios dos ciclos escolares no país. Estudos Avançados, São Paulo, v. 15, n. 42, p. 103-140, maio/ago. 2001.

CAnÁRIo, Rui et al. (Org.). Escola da Ponte: um outro caminho para a educação. São Paulo: Didática Suplegraf, 2004.

CÂNDIDO, Antônio. A estrutura da escola. In: Pereira, Luiz; Foracchi, Marialice M. Educação e sociedade: leituras de sociologia da educação. 6. ed. São Paulo: Ed. Nacional, 1974. p. 107-128.

DAmásio, António R. O erro de Descartes: emoção, razão e o cérebro humano. 2. ed. São Paulo, Companhia das Letras, 2009.

Esteban, Maria Teresa. Provinha Brasil: desempenho escolar e discursos normativos sobre a infância. Sísifo. Revista de Ciências da Educação, Lisboa, n. 9, p. 47-55, maio/ ago. 2009.

Freinet, Célestin. A educação do trabalho. São Paulo: Martins Fontes, 1998.

JaComini, Márcia Aparecida. Educar sem reprovar. São Paulo: Cortez, 2010.

KANDEL, Eric R. Em busca da memória: o nascimento de uma nova ciência da mente. São Paulo: Companhia das Letras, 2009.

Pacheco, José. Lições da Ponte [Entrevista]. Revista Educação, São Paulo, n. 146, jun. 2009. Disponível em: <http://revistaeducacao.uol.com.br/textos.asp?codigo=12706>. Acesso em: 16 jun. 2009.

PARO, Vitor Henrique. Por dentro da escola pública. 3. ed. São Paulo: Xamã, 2000. 
. Educação para a democracia: o elemento que falta na discussão da qualidade do ensino. In: Escritos sobre educação. São Paulo: Xamã, 2001. p. 33-47.

. Reprovação escolar: renúncia à educação. 2. ed. São Paulo: Xamã, 2003.

. Educaşão como exercício do poder: crítica ao senso comum em educação. 2. ed. São Paulo: Cortez, 2010a.

. Estrutura da escola e educação como prática democrática. São Paulo: FEUSP, 2010b. 179p. (Relatório de Pesquisa).

SousA, Sandra Zákia. Avaliação, ciclos e qualidade do ensino fundamental: uma relação a ser construída. Estudos Avançados, São Paulo, v. 21, n. 60, p. 27-44, maio/ago. 2007.

STAKE, Robert E. Pesquisa qualitativa/naturalista: problemas epistemológicos. Educação e Selę̧ão, São Paulo, n. 7, p. 19-27, jun. 1983.

TeiXeIRA, Anísio S. Nota preliminar. In: Kessel, Moysés I. A evasão escolar no ensino primário. Revista Brasileira de Estudos Pedagógicos, Rio de Janeiro, v. 22, n. 56, p. 53-55, out./dez. 1954.

WhiteheAd, Alfred North. Fins da educação e outros ensaios. São Paulo: Nacional, 1969 (1. ed. 1929).

\section{SOBRE O AUTOR}

Vitor Henrique Paro é doutor em educação pela Pontifícia Universidade Católica de São Paulo (PUC-SP). Professor titular da Universidade de São Paulo (USP).

E-mail:vhparo@usp.br 
data: GERES 2005 - LOED / FE / UNICAMP < http://www.geres.ufmg.br/> and Vulnerability-NEPO/UNICAMP < http://www.nepo.unicamp.br/vulnerabilidade/>. Using theoretical references that support the concepts of Social Vulnerability, Spatial Segregation, Neighborhood Effects and School Quality, analyzed the distribution of schools within different areas of vulnerability, relating this distribution to the results of their performance measured by "aggregate value". The methodology used was with 1) a description of the variables related to characteristics around the schools, 2) the intersection of performance and features found in these schools. The results revealed that there not is a regular evidence relation between the spatial layout of the schools and their performance.

Keywords: social vulnerability; school quality; spatial segregation; neighborbood effect.

\section{Escuelas municipales de Campinas y la vulnerabilidad sociodemográfica: primeras aproximaciones}

Este trabajo discute la distribución de escuelas municipales de Campinas, São Paulo - Brasil, según su localización espacial y desempeño escolar, a partir de los datos de las pesquisas: GERES 2005 - LOED / FE / UNICAMP <http://www.geres. ufmg.br/> y Vulnerabilidad - NEPO / UNICAMP < http://www.nepo.unicamp. br/vulnerabilidade/>. Utilizando referenciales teóricos que sustentan los conceptos de Vulnerabilidad Social, Segregación Espacial, Efecto Hogar y Efecto Escuela, analizamos la distribución de las escuelas dentro de las diferentes zonas de vulnerabilidad, relacionando esa distribución a los resultados de su desempeño medido por el "valor añadido". La metodología utilizada se dio en dos ejes: 1) la descripción de las variables relacionadas a las caracteristicas del entorno de las escuelas; 2) el cruce de las características encontradas y el desempeño de esas escuelas. Los resultados revelaron que no hay una recurrencia clara en relación a la disposición espacial de las escuelas relacionadas a su desempeño.

Palabras clave: vulnerabilidad social; eficacia escolar; segregación espacial; efecto hogar.

\section{VITOR HENRIQUE PARO}

\section{Progressão Continuada, Supervisão Escolar e Avaliação Externa: implicações para a qualidade do ensino}

Derivado de estudo mais amplo sobre a estrutura da escola, este artigo discute resultados de pesquisa de cunho qualitativo realizada em escola pública fundamental sobre questões relacionadas à progressão continuada, à supervisão escolar e à avaliação externa. Tendo presente seu relacionamento com a qualidade do ensino e com a avaliação escolar, esses temas são tratados a partir de um conceito de educação como prática democrática, procedendo-se à crítica da prática pedagógica tradicional. Os dados e análises sugerem que, quanto à progressão continuada, se enfatize a efetividade do ensino, em lugar da passagem 
ou reprovação de série; com relação à supervisão escolar, se procure desenvolver suas potencialidades de avaliação, assessoria e apoio à prática pedagógica escolar e, com respeito à avaliação externa, se ultrapassem seus estreitos limites atuais, promovendo sua articulação com a supervisão escolar, de modo a superar a mera realização massiva de provas e testes.

Palavras-chave: avaliação escolar; supervisão escolar; qualidade do ensino; ensino fundamental.

\section{Continuous Progress, School Supervision, External Evaluation: implications for the quality of education}

Being part of a broader study about the structure of the school, this article presents and discusses some results of a qualitative research carried out in elementary public school about issues related to continuous progress, to school supervision and external evaluation. Considering their relationship with the quality of education and with school evaluation, these themes were treated based on a concept of education as a democratic practice, proceeding to a critique of the traditional pedagogical practice. Data and analysis suggest that, concerning continuous progress, effectiveness of education should be emphasized instead of passing or falling a year; in relation to school supervision, a development of its potentialities of evaluation, counseling and support to the pedagogical school practice should be pursued; and, in relation to external evaluation, its narrow current boundaries should be enlarged making it possible to go over the simple massive application of tests.

Keywords: school evaluation; school supervision; quality of education; primary school.

\section{Progresión Continuada, Supervisión Escolar y Evaluación Externa: implicaciones para la cualidad de la enseñanza}

Derivado de estudio más amplio sobre la estructura de la escuela, este artículo discute resultados de investigación cualitativa, realizada en escuela pública fundamental, sobre cuestiones relacionadas a progresión continuada, supervisión escolar y evaluación externa. Considerando su relación con cualidad de la enseñanza y evaluación escolar, esos temas son tratados desde un concepto de educación como práctica democrática, criticando la práctica pedagógica tradicional. Los datos y análisis sugieren que, cuanto a la progresión continuada, se enfatice la efectividad de la enseñanza en lugar de la aprobación o reprobación de grado; con relación a la supervisión escolar, que se procure desarrollar sus potencialidades de evaluación, asesoría y apoyo a la práctica pedagógica escolar y, con respeto a la evaluación externa, que se ultrapasen sus estrechos limites actuales, promoviendo su articulación con la supervisión escolar, de modo a superar la simple realización masiva de pruebas y testes.

Palabras clave: evaluación escolar; supervisión escolar; cualidad de la enseñanza; enseñanza fundamental. 